\title{
O cinema na escola e o aluno-espectador: leituras, imagens e subjetividades a partir do filme O Fim e o Princípio
}

\author{
Marcelo Vicentin* \\ Jackeline Mendes Rodrigues ${ }^{* *}$
}

\begin{abstract}
Resumo
O artigo é parte de um estudo de dissertação de mestrado que teve como foco discutir as relações entre o cinema e a educação a partir dos movimentos curriculares da Secretaria de Educação do Estado de São Paulo (SEE-SP), em particular o projeto Cultura é currículo, ao qual é subordinado o projeto O cinema vai à escola. Para essa discussão foi tomado como tripé a Modernidade, através da crítica desenvolvida por Nietzsche e Foucault; o Currículo, sob o viés das perspectivas pós-críticas e o Cinema, observando-o em suas origens, repleta de perspectivas técnicas-científicas ao momento contemporâneo. Através de uma analítica discursiva foram problematizadas, as subjetividades que são movimentadas nesta proposta bem como os processos identitários que emergem da presença da linguagem cinematográfica na prática escolar. Neste texto, apresentaremos um recorte do estudo em que problematizamos o sujeito do acontecimento, da experiência vivenciada na projeção. Um contraponto à proposta oficial, em que o texto é tomado por outras personagens, por outras vozes; aqui a de um professor e a de seus alunos, todos nos principais papéis, sem coadjuvantes. Assim, pretendemos olhar para este encontro, de outro lugar, outra posição, com outros olhos: os que marejam.
\end{abstract}

Palavras-chave: currículo; cinema; identidade; subjetividade.

\section{The cinema in school and student-spectator: readings, images and subjectivities from movie the end and the beginning}

\begin{abstract}
The paper is part of a dissertation study that focused on discussing the relationship between cinema and education from the curriculum movements of the Secretaria do Estado de São Paulo (SEE-SP), in particular the project Culture is curriculum, which is under the project Cinema goes to school. For this discussion was taken as tripod Modernity, through criticism developed by Nietzsche and Foucault; Curriculum, under the bias of postcritical perspectives and the Cinema, watching him in its origins, full of technical-scientific perspectives to contemporary time. Through a discursive analysis, subjectivities that are moved in this proposal were problematized and as well as identity processes that emerge from the presence of film language in school practice. In this paper, we present part of research where we problematized subject of the event, the experience in projecting. A counterpoint to the official proposal, in which the text is taken by other characters, other voices; here there are a teacher and their students, all in the lead roles, without coadjuvants. Thus, we intend to look at this meeting, from another place with different eyes: those who weep.

Keywords: curriculum; cinema; identity; subjectivity.
\end{abstract}

\section{Argumento}

Para nós, o cinema é um produto industrial e também arte; extremos irreconciliáveis, como indica Aumont (2008), mas que mantêm a ambição de se encontrarem. Aqui propomos observá-lo como objeto artístico, como potência transgressora e de resistência cultural; mas também como campo de representações, de possibilidades para a organização e socialização do mundo, de valores morais e éticos, proporcionando outros e diferentes olhares.

Buscamos é provocar, deslocar, desestabilizar o olhar do espectador para um encontro com o outro, com a alteridade; com seus medos e modos; com o perceber e ser percebido; com um universo escolar múltiplo e fragmentado. Aqui o cinema procura propiciar que diferentes vozes se apresentem e dialoguem, para que os problemas, as diferenças e o outro que estão fora do espaço escolar ocupem-no.

Para tanto, nos é importante o conceito de autoria proposto por De Certeau, em que "um mundo diferente (o do leitor) se introduz no lugar do autor" (2009, p. 48). Subjetivismo este que também se encontra no material destinado à formação dos professores, como observado por Araújo: "Nós, espectadores [...], não devemos nos preocupar excessivamente com as opiniões dos

* Endereço eletrônico: vicentinmarcelo@ gmail.com

** Endereço eletrônico: Jackeline.mendes@ usf.edu.br 
críticos e especialistas. Embora elas mereçam ser levadas em conta, a experiência que temos de um filme é muito pessoal (e, portanto, subjetiva)." (apud CADERNO DO CINEMA DO PROFESSOR UM, 2008, p. 114). Esta situação nos permite retomar o conceito espectador-aluno ${ }^{I}$ em contraponto à aluno-espectador, a fim de que possamos observar os atravessamentos proporcionados pela experiência cinematográfica, em contrapartida a um linear antes/durante/depois do filme.

\section{Roteiro, locações, atores.}

Este estudo ocorreu em uma escola e uma cidade não tão diferente de tantas outras cidades do Brasil, visto que dos 5.565 municípios brasileiros, 4.000 municípios têm menos de 20.000 habitantes e estão fora do mercado distribuidor cinematográfico por não apresentarem viabilidade econômica para manterem comercialmente suas salas de cinema.

A escola aqui tratada, trabalha com matrículas do Ensino Fundamental 2 (EF2), que abrange do $6^{\circ}$ ao $9^{\circ}$ ano (antigas $5^{\mathrm{a}}$ à $8^{\mathrm{a}}$ séries), e Ensino Médio (EM). Nosso grupo foi formado por alunos da EJA. Um grupo que em certas circunstâncias se apresenta heterogêneo ou homogêneo. Há heterogeneidade na faixa etária, no gênero, nos gostos, nos desejos; homogeneidade em relação ao local de nascimento e pertencimento - a grande maioria de $80 \%$ a $90 \%$ são nascidos e criados na cidade em questão; bem como serem oriundos do campo, do meio rural.

Como observado por Maya e Dayrell (2011), estes grupos atravessam o espaço escolar de diferentes modos e ritmos, em alguns momentos ocasionando um choque sociocultural mais acentuado entre as gerações. Mas há também relações fraternas, de amizade. Deste modo, a sala de aula se torna um espaço de alteridade que obriga a aprender a conviver. Alguns que não conseguem se adaptar as diferenças, desistem temporária ou definitivamente da escola.

Durante os anos letivos de 2010 e 2011, diversos alunos do EF2 e EM da EJA assistiram a diversos filmes com diferentes temáticas dentro da disciplina de língua portuguesa: a adolescência, a migração, a violência e a velhice. Cada tema foi composto por um grupo de, no mínimo, quatro filmes falados originalmente em português. Cabe observar que poucos filmes deste conjunto estão entre os disponibilizados pela SEE-SP.

De todo este conjunto de filmes, apenas um será tratado aqui: o filme de Eduardo Coutinho, $O$ fim e o princípio, que "fala sobre a história de vida do povo da Paraíba" (KUBRICK) e "sobre a vida do povo do campo do sertão" (JODOROWSKY).

Tal escolha decorreu do fato de estar entre os filmes disponibilizados pela SEE-SP, e por atender ao projeto desenvolvido pelo professor, que buscou a partir de determinadas temáticas, apresentar as diferentes construções do falar brasileiro.

$O$ fim e o princípio encerrou a programação em que o tema central dos filmes tratava da questão de adultos e idosos na sociedade brasileira. Nesse período foram também exibidos: $O$ outro lado da rua (2004), de Marcos Bernstein; Chega de saudade (2007), de Lais Bodanski; Depois daquele baile (2005), de Roberto Bomtempo; Bendito fruto (2004), de Sergio Goldenberg; Reflexões de um liquidificador (2010), de André Klotzel.

\section{Lentes e planos}

A linguagem cinematográfica é uma possibilidade para promover a percepção sobre assuntos diversos, intercedendo ${ }^{3}$ para uma reflexão que possibilite o reconhecimento de diferenças linguísticas e o direito à diversidade social, possibilitando o diálogo entre pessoas e grupos pertencentes a universos culturais diferentes (BAGNO, 2003).

Nosso professor, como observa Ellsworth (2001), convida o aluno a assumir um olhar determinado sobre o filme. Ele também vive esse papel por programar, endereçar os filmes aos alunos. E por mais que o faça com a intenção de promover um olhar sobre um outro na língua que o atravessa, constitui, identifica, este controle não se concretiza, pois o aluno é atravessado por identidades culturais e sociais que interferem em sua leitura do filme, tornando impraticável um ajuste entre o articulado e seu resultado.

Mas para perceber o seu engano foi necessário que o professor percebesse que enquanto endereçava a questão da identidade pela língua, pelos preconceitos e estereótipos linguísticos, os alunos articulavam questões de diferença, de alteridade, percebendo a si e aos outros, a forma como agem sobre "a história e na história" (Op. cit., p. 43).

Para Eduardo Coutinho - diretor de $O$ fim $e o$ princípio - as circunstâncias de uma filmagem permitem perceber as contingências que estão por trás das "verdades", das histórias, das fábulas que as pessoas (re)criam. Deste modo suas personagens 
têm a possibilidade de se expressarem sobre o que quiserem e como vêm os fatos, sobre o que acreditam, o que não acreditam ou que talvez gostariam de acreditar. Uma das características dos seus filmes é não ter um roteiro definido, assim ele pode alterar seus projetos de acordo com os acontecimento e experiências que vivencia durante o processo de pesquisa ou de filmagem. Tal qual a Coutinho, nosso professor não se prendeu a seu roteiro e reorientou o projeto: deixar as vozes dos alunos serem preponderantes, serem reflexo de experiências vividas, sentidas. De acordo Ellsworth (2001, p. 44), “o poder do endereçamento não é algo que os professores possam dominar, controlar, predizer ou transformar em tecnologia".

O professor percebeu que sua voz ressoava sobre as demais, logo para que o filme pudesse agir o mais livremente possível sobre as identidades dos alunos, ele deveria silenciar a sua voz. Isso não impedia o endereçamento, pois continuou a programar os filmes, mas ao silenciar-se procurou não manipular o "entre-espaço" (Op. cit., p. 45) entre ele e os alunos, entre os alunos e os filmes.

$\mathrm{O}$ endereçamento como uma relação de poder é sempre presente, a diferença é atenuar a manipulação a ponto de quase não existir, tornar o endereçamento um acontecimento. Acontecimentos que se iniciam nas escolhas dos filmes pelo professor, pois produzem indiretamente um discurso. Ferrari (2012) observa que neste ato se produz uma ação sobre o corpo escolar em que um determinado saber, produto de uma intencionalidade age sobre as experiências dos corpos e sujeitos.

Como acontecimento entra em jogo "a transmissão no sentido de dar e receber, de dar e tomar, dar a palavra e de receber a palavra e de tomar a palavra, do que acontece na transmissão do dom da língua" (LARROSA, 2011, p. 282). Deste modo, nosso professor procurou diversas maneiras para que a sua voz não se colocasse sobre as vozes dos alunos, e assim, que as suas experiências e vivências não manipulassem, interferissem nas produções textuais dos alunos: único compromisso dos alunos para com o professor. Um convite para uma produção textual a cada exibição. Próximo a Eduardo Coutinho, "convida para fazer um filme" (EASTWOOD), ou "pedia permissão pra entrar nas casas para conversar a respeito de cada família" (JODOROWSKY). Sem regras, sem normas, buscando os sentidos, sejam estes bons ou maus.

Dar a palavra, tomar a palavra; roteiro para perceber como as identidades, as subjetividades dos sujeitos escolares foram atravessadas pelos filmes, por isso a necessidade de permitir o livre pensar sobre algum tema, objeto ou conceito. Acreditamos na multiplicidade do dizer, sentir, expressar, extrapolando as linhas, os espaços que nos contém, possibilitando que o espectador e o aluno se encontrem, se fundam, se congreguem naquilo que têm em comum, serem "participantes reais no processo de atribuição de sentido" (ELLSWORTH, 2001, p. 57). O que já denominamos anteriormente de espectador-aluno.

Por conseguinte, os textos produzidos pelos alunos ${ }^{4}$ geram pistas para diferentes discursos e diferentes identidades no espaço escolar. São discursos, o lugar onde "se concentram, se intricam e se confundem, como um verdadeiro nó, as questões relativas à língua, à história e ao sujeito" (FERREIRA, 2010, p. 1); pistas do acontecimento, da experiência cinematográfica atuando sobre a subjetividade dos alunos. Como observa Luz (apud FRANÇA, 2005, p. 34): "Mais que representação fiel ou não da realidade [...], o filme oferece ao espectador um campo de experiências e só ganha existência se efetivar um sujeito para este campo".

Ver e escrever sobre filmes, é escrever sobre o mundo, a vida. Seja pela escrita ou pela oralidade. Assim nos constituímos por aquilo que dizemos e escrevemos, quanto por aquilo que dizem, escrevem sobre nós. Somos discursos. Foucault (2012b), ao refletir sobre aspectos da escrita de si, observa o fato de escrever para si e para outro se dá como um exercício, um treino. Escrever sobre si é um exercício de/sobre a vida, um modo de oferecer "aquilo que se fez ou se pensou a um olhar possível" (Op. cit, p. 142).

\section{As palavras: cenas que escapam}

O fim e o princípio (2005) é um filme sobre um cotidiano simples atravessado por questões filosóficas, em que as personagens relatam, opinam, apresentam concepções sobre o mundo que as cerca, tratando de temas como o amor, a fé, as crenças, o trabalho, a família, a vida, a morte. Coutinho busca do que há de singular nas pessoas através de entrevistas, tornando-as um acontecimento, sem previsibilidade definida; um cinema em que a palavra se torna múltipla: uma ação de dar/tomar a palavra (LARROSA, 2011).

Ao conversar com as personagens, produz um acontecimento em que ouve as histórias que lhe são contadas sem julgar ou emitir juízo de valores. Sem amarras e medos, as personagens falam sobre si, suas vidas, de momentos felizes ou tragédias. 
Filmam-se palavras, rostos, gestos; as histórias das pessoas. Não há limites, a opção é pelo único, singular, frágil do acontecimento. A cada entrevista, a cada história, somos apresentados ao outro, ao diferente, sem estigmas, sem estereótipos.

Fischer (2012) observa que Foucault ${ }^{5}$ problematizou a produção de discursos sobre aqueles que levam uma vida singela ou se tornaram indesejados; vidas que vão sendo apagadas, mas quando transformados em texto são percebidos pelo corpo social que fazem parte. Quando Coutinho abre o diafragma da câmera para os rostos e as vozes dos moradores do Sítio Araçá, ele garante a eternidade para estas imagens, visto que estão presas a uma narrativa que lhes possibilitou visibilidade. Para Fischer (2012a, p. 151):

São pessoas que teriam desaparecido se não tivessem momentaneamente se defrontado com o poder. [...] foram para sempre fixadas em narrativas nas quais se tornaram visiveis. São histórias que movimentam o leitor por se tratar de histórias de vida, de desgraça, loucura e morte que carregam em si beleza e assombro, justamente porque registradas em breves textos que marcam o destino de vidas efetivamente "reais".

As histórias são narradas no embate entre as memórias marcadas no corpo e na oralidade das personagens. O lugar continua o mesmo, seco e com casas simples, "um outro mundo bem diferente do que nós vivemos aqui" (GLAUBER), uma vida que continua difícil, ou seja, "a vida de povo nordestino um povo sofrido" (DREYER), em que "tudo era dificio com a alimentação o trabalho na roça, quando nacia o mais velho sábia se iria crecer ou não" (FELLINI).

A diferença pode fundamentar a incompreensão, como ser um exercício de convivência. Ao nos aproximarmos de outras representações, promovendo novos significados e valores aos anteriormente construídos, podemos avançar sobre as fronteiras espaciais e temporais, quebrando estereótipos e preconceitos ligados àqueles moradores da comunidade do Sítio Araçá, uma representação de todo sertão nordestino. Coutinho ao encontrar as suas histórias, encontra a alteridade, ele e sua equipe são os outros, "Um jornalismo que foi fazer uma matéria sobre o sertão" (GRIFFITH); "esse grupo que moravam no Rio de Janeiro" (BUÑUEL).

O filme desmonta os estereótipos, rompe as fronteiras, pois "pensa aquela gente, quais são seus valores mais intrínsecos. No final da sessão o cidadão urbano sai impressionado com o que ouviu dos próprios moradores" (FERRAZ, 2005, s/n); "todos deviam assistir esse filme para a pessoa refletir como é a vida lá fora no sertão nordestino e aprender um pouco com eles" (DREYER). Estereótipos abundantes nos meios midiáticos, traduzidos pela miséria, fome, ausência de um saber escolarizado; de um passado vivido - "muitos lugares ainda existe, nas regiões nordestinas. Naquela época não era desenvolvido tinha muitas situação ruim" (ALTMAN, um dos nossos migrantes), a um presente sentido - "eu fiquei com muita dó dos velhinhos coitados eles moram numa casa bem antiga não tem nem televisão tinha varal de fiu para poder estender" (BABENCO).

Além das imagens, as palavras, o modo de falar que distingue entre o nós e o eles, estabelece diferenças, como as percebe nossos alunos migrantes: "tem pessoas que falam coisas que para quem é daqui do sul do país não sabe nada do que eles falam porque é uma linguagem bem diferente" (GLAUBER); "Na linguagens dos sertanejos do sertão. [...] alinguagens atrapalhada, dificuldade para o moço do cinema entender" (ALTMAN). Linguajar diferente, estranho. "Para mim isto não é uma novidade porque eu sou do nordeste" (GLAUBER).

Estranheza que o diretor do filme relatou para Frochtengarten (2009), "a língua que se fala no Nordeste parece estranha é porque empregam palavras do português arcaico que nós esquecemos. [...] Ninguém no Rio ou em São Paulo sabe o que quer dizer". Uma linguagem de um mundo perdido, esquecido, de um mundo anterior que parece distante do presente; "muita gente falam uma lingua que hoje quase ninguém intende o que quer dizer" (FELLINI).

A percepção, o reconhecimento desses idosos como pessoas que nós possamos ou queiramos ser, projeta-nos sobre a narrativa do outro, "esse povo eles viviam muitos anos, hoje as pessoas não conçege chegar na idade desse povo" (DREYER); um mundo muito diferente do atual, "durante o tempo passado o povo vivia compretamente diferente e durava mais" (FELLINI), um mundo em que os valores, as regras, as condutas diferem daquilo que conhecemos e praticamos atualmente. Um mundo anterior e esquecido representado nos laços que o mantém e só se desfazem com a morte do outro: "zéca um outro homem que conhesceu a mulher com 18, e ela tinha 26 anos e ate oge eles 
vevem juntos" (EASTWOOD).

Se para os idosos do filme as relações afetivas foram primordiais para uma vida mais longa e profícua, também a fé se mostrou essencial para os dissabores da vida: "um povo que tem muita fé, e acredita que Deus seja a solução de todos após a morte" (FELLINI). O momento final para todos, momento da finitude expressado no título do filme, momento final na vida dessas pessoas reais. Uma jornada que se desenvolve pelas reminiscências, pelas memórias mantidas vivas na oralidade das personagens.

Memórias que revolveram outras memórias, outros sentidos, outras representações, ora de dificuldades e dissabores com o mundo atual, ora na possibilidade de esperança, na chama presente em corpos e almas que o tempo apenas consumiu, mas de existência plena, de alegria e de felicidade: "no sertão da paraiba é tão seco mas o pessoal é muito feliz. isso é o importante" (EASTWOOD), "cada um feliz com sua vida e com seu casamento que passou e com sua historia de sofrimento que não se arrepende de ter vivido" (GRIFFITH), "mostra a realidade do sertão do nordeste brasileiro, onde as pessoas são bem simples, naquelas casas humildes, mais mesmo assim ainda são alegres" (GLAUBER).

Os diálogos entre Coutinho e seus entrevistados conduziram para um passado, para um tempo vivido e para a compreensão de finitude que se mostra nas marcas que os corpos carregam. Mas não para uma velhice associada ao final da existência: "É muito interessante para nós que hoje vivemos algum esempro para nos e uma historia de vida muito interessante" (GRIFFITH, um dos jovens).

\section{Cenas finais}

Os textos produzidos pelos alunos tornaramse fragmentos, partes soltas de suas vidas, descolados da "alma" a partir do acontecimento fílmico. Memórias pegas ao acaso, não a rememoração de algo acontecido, mas memórias que no momento foram sentidas como verdadeiras. Coutinho (apud FROCHTENGARTEN, 2009, p. 28), observa que "a memória é a coisa mais mentirosa do mundo. $\mathrm{O}$ que não quer dizer que não seja verdadeira". São fragmentos produzidos no acontecimento, das experiências, das vivências.

Para Foucault (2012b), o processo de escrita acontece através daquilo que se pode ouvir, ler, ver, e elas não se dissociam; acontecem simultaneamente, constituindo-se em uma experiência sobre o pensamento, trazendo à tona o que está gravado na alma, que se transforma em uma arte da verdade, de produzir a verdade por si mesmo. "Escrever é, portanto, 'se mostrar', se expor, fazer aparecer seu próprio rosto perto do outro" (Op. cit., p. 152). Deste modo, em cada corpo, em cada pessoa, havia "histórias como é no dia dia" (JODOROWSKY), "apontando o seu sofrimento do dia a dia, cada caso que foi contado simples-mente foram acontecidos" (ALTMAN); histórias que "estória de vida diferente de cada família" (GRIFFITH).

Histórias que serviram para captar o já dito com a finalidade de constituir a si. Textos que relatam experiências, reflexões sobre consigo, escritos para si e para os outros. O importante aqui não é o gênero pelo qual o texto possa ser classificado, visto que não importa uma taxionomia do filme pelo aluno, mas o revelar dos sentimentos, sensações e afetos, com a escrita constituindo-se em um exame sobre o que se passa no corpo e na alma.

Retomando Foucault (2012b, 2012c), uma estética da existência reside no agir, na arte como elaboração e aparência, que se constrói e elabora; uma tarefa que cabe ao sujeito. Deste modo, destaca-se a imaginação para produzir e se produzir, aproximando as fronteiras entre o nós e os outros. A ética, a estética da existência se constitui nos sentidos que vão sendo retomados e recriados.

Larrosa (2009) ao analisar a obra de Nietzsche e sua relação para com a educação observa que nossa inteligibilidade do mundo é múltipla pelo fato de sermos textos, palavras, discursos, e isso permite interpretações infinitas sobre o que nos cerca. Mas quando falamos do homem precisamos que outros nos mostrem ou digam; precisamos da arte, do exercício estético para podermos ler e interpretarmo-nos, permitindo olharmos para o mundo e para nós, atravessando e movimentando nossas identidades, nossas memórias. Fragmentos que se tornam planos, cenas, sequências de um filme particular; fragmentos de si, escritas de si, que são momentos nossos e para os outros.

\section{Notas}

1 Este conceito é proposto na dissertação e procura observar dinâmicas diferentes na relação currículo e sujeito, propondo que o sujeito sempre se coloca em primeiro plano em relação ao currículo. E o espectador, para nós, sempre escapa às determinações. 
2 Em toda a sua extensão, sempre que forem feitas menções a escritos ou falas dos alunos, estas estarão marcadas por codinomes de diretores de cinema: Buñuel, Kubrick, Babenco, Eastwood, Griffith, Altman, Glauber, Jodorowsky, Coppola, Truffaut, Dreyer, Fellini.

3 Diferentemente à mediação, a intercessão "é uma potência para algo que vai ser produzido a partir de algo" (CARVALHO, 2011, p. 10).

4 Como já observado, para cada filme exibido aos alunos, estes deveriam produzir textos sobre o que lhes impressionava no filme em questão. Aqui, os textos sobre $O$ fim e o princípio.

5 In: A vida dos homens infames.

\section{Referências}

AUMONT, Jacques. Moderno? Por que o cinema se tornou a mais singular das artes. (Trad.) RIBEIRO, Eloisa Araújo. Campinas: Papirus, 2008.

BAGNO, Marcos. Preconceito linguístico: o que é, como se faz. 22. ed., São Paulo: Loyola, 2003.

CARVALHO, Alexandre F. de. Função Educador: em busca de uma noção intercessora a favor das experiências de subjetividades ativas. Michel Foucault: Transversais entre educação, filosofia e história. Belo Horizonte: Autêntica, 2011, p. 923.

De CERTEAU, Michel. A invenção do cotidiano: artes de fazer. (Trad.) ALVES, Ephraim Ferreira. 16. ed. Petrópolis: Vozes, 2009.

ELLSWORTH, Elizabeth. Modos de endereçamento: uma coisa de cinema; uma coisa de educação também. Nunca fomos humano: nos rastros do sujeito. (Org.; Trad.) SILVA, Tomaz Tadeu da. Belo Horizonte: Autêntica, 2001, p. 7-76.

FERRARI, Anderson. Cultura visual e homossexualidades na constituição de novas infâncias e novos docentes. Revista brasileira de educação. V. 17., n. 49., jan.-abr. 2012, p. 107-120.

FERRAZ. Costa. O fim e o princípio na terra do fim do mundo. Revista raiz, n. 1, nov. 2005. Disponível em <http://revistaraiz.uol.com.br/portal/index.php? option=com_content\&task= view\&id=58\&Itemid=72>. Acesso em dez. 2012.
FERREIRA, Maria Cristina L.. Análise do discurso e suas interfaces: o lugar do sujeito na trama do discurso. Organon. v. 24., n. 48., jam.-jul. 2010. Disponível em: <http://seer.ufrgs.br/organon/article/view/28636/17 316>. Acesso em jul. 2011.

FISCHER, Rosa M. B.. O visível e o enunciável: contribuições do pensamento foucaultiano aos estudos de comunicação. Trabalhar com Foucault: arqueologia de uma paixão. Belo Horizonte: Autêntica, 2012, p. 133-146.

FOUCAULT. Michel. A ordem do discurso. (Trad.) SAMPAIO, Laura F. de A. ed. 21. São Paulo: Loyola, 2011c.

O uso dos prazeres e as técnicas de si. Ditos e escritos, vol. V: ética, sexualidade, política. (Org.) MOTTA, Manoel B. de, (Trad.) MONTEIRO, Elisa; BARBOSA, Inês A. D. 3. ed. Rio de Janeiro: Forense Universitária, 2012, p. 187211.

Uma estética da existência. Ditos e escritos, vol. V: ética, sexualidade, política. (Org.) MOTTA, Manoel B. de, (Trad.) MONTEIRO, Elisa; BARBOSA, Inês A. D. 3. ed. Rio de Janeiro: Forense Universitária, 2012a, p. 281-286.

A escrita de si. Ditos e escritos, vol. V: ética, sexualidade, política. (Org.) MOTTA, Manoel B. de, (Trad.) MONTEIRO, Elisa; BARBOSA, Inês A. D. 3. ed. Rio de Janeiro: Forense Universitária, 2012b, p. 147-162.

. A ética do cuidado de si como prática de liberdade. Ditos e escritos, vol. V: ética, sexualidade, política. (Org.) MOTTA, Manoel B. de, (Trad.) MONTEIRO, Elisa; BARBOSA, Inês A. D. 3. ed. Rio de Janeiro: Forense Universitária, 2012c, p. 258-280.

FRANÇA, Andréa. Foucault e o cinema contemporâneo. Revista Alceu. Rio de Janeiro: v. 5, n. 10, jan. - jul. 2005, p. 30-9. Disponível em: $<$ http://revistaalceu.com.pucrio.

br/medialalceu_n10_andrea.pdf $>$. Acesso em 08 ago. 2012

FROCHTENGARTEN, Fernando. A entrevista como método: uma conversa com Eduardo Coutinho. Psicol. USP, São Paulo, v. 20, n. 1, mar. 
2009. Disponível em <http://www. revistasusp.sibi.usp.br/scielo.php?script=sci_arttext \&pid=S1678-51772009000100008\&

lng=pt\&nrm=iso>. acesso em $10 \mathrm{dez} .2012$.

LARROSA, Jorge. Notas sobre a experiência e o saber de experiência. Revista Brasileira de Educação, n. 19, Jan./Fev./Mar./Abr. 2002.

Sobre a lição: ou do ensinar e do aprender na amizade e na liberdade. Pedagogia profana: danças, piruetas e mascarados. (Trad.) VEIGANETO; Alfredo. 5. ed. Belo Horizonte: Autêntica, 2010, p. 139-146.

; SKLIAR, Carlos. Babilônios somos: a modo de apresentação. Habitantes de Babel: políticas, poéticas da diferença. (Orgs.) LARROSA, Jorge; SKLIAR, Carlos. (Trad.) VEIGA, Semíramis G. da. Belo Horizonte: Autêntica, 2011, p. 7-30.

- Dar a palavra: notas para uma dialógica da transmissão. Habitantes de Babel: políticas, poéticas da diferença. Orgs.) LARROSA, Jorge; SKLIAR, Carlos. (Trad.) VEIGA, Semíramis G. da. Belo Horizonte: Autêntica, 2011, p. 281-295.

MAYA, Carla L.; DAYRELL, Juarez. Juventude e relações intergeracionais na EJA: apropriações do espaço escola e sentidos da escola. Educação e seus atores: experiências, sentidos e identidades. Belo Horizonte: Autêntica, 2011, p. 117-139.

\section{Sobre os autores:}

Marcelo Vicentin: Doutorando em Educação (2014) Mestre em Educação (2013), Especialista em Mídias na Educação (2012), Bacharel em Cinema (1995), com formação complementar em Língua Portuguesa. Trabalhos com atividades ligadas à difusão cinematográfica brasileira e ao núcleo de comunicação e educação da USP (NCE-USP) Professor de Língua Portuguesa na Rede Estadual Paulista e no Colégio Objetivo de Bragança Paulista.

Jackeline Rodrigues Mendes: Possui graduação em Licenciatura em Matemática pela Universidade Estadual de Campinas (1987), mestrado em Linguística Aplicada na área de Educação Bilíngue pela Universidade Estadual de Campinas (1995) e doutorado em Linguística Aplicada na área de Educação Bilíngue pela Universidade Estadual de Campinas (2001). Atualmente é professora do PPGE da Universidade São Francisco.

Recebido em: 15/04/2014

Aprovado em: 05/12/2014 